\title{
Low- and high-level controlled processing in executive motor control tasks in 5-6-year-old children at risk of ADHD
}

Citation for published version (APA):

Kalff, A. C., de Sonneville, L. M., Hurks, P. P. M., Hendriksen, J. G. M., Kroes, M., Feron, F. J. M., Steyaert, J. G. P. L. E., van Zeben, T. M., Vles, J. S. H., \& Jolles, J. (2003). Low- and high-level controlled processing in executive motor control tasks in 5-6-year-old children at risk of ADHD. Journal of Child Psychology and Psychiatry, 44(7), 1049-1057. https://doi.org/10.1111/1469-7610.00189

Document status and date:

Published: 01/01/2003

DOI:

10.1111/1469-7610.00189

Document Version:

Publisher's PDF, also known as Version of record

Please check the document version of this publication:

- A submitted manuscript is the version of the article upon submission and before peer-review. There can be important differences between the submitted version and the official published version of record.

People interested in the research are advised to contact the author for the final version of the publication, or visit the DOI to the publisher's website.

- The final author version and the galley proof are versions of the publication after peer review.

- The final published version features the final layout of the paper including the volume, issue and page numbers.

Link to publication

\footnotetext{
General rights rights.

- You may freely distribute the URL identifying the publication in the public portal. please follow below link for the End User Agreement:

www.umlib.nl/taverne-license

Take down policy

If you believe that this document breaches copyright please contact us at:

repository@maastrichtuniversity.nl

providing details and we will investigate your claim.
}

Copyright and moral rights for the publications made accessible in the public portal are retained by the authors and/or other copyright owners and it is a condition of accessing publications that users recognise and abide by the legal requirements associated with these

- Users may download and print one copy of any publication from the public portal for the purpose of private study or research.

- You may not further distribute the material or use it for any profit-making activity or commercial gain

If the publication is distributed under the terms of Article $25 \mathrm{fa}$ of the Dutch Copyright Act, indicated by the "Taverne" license above, 


\title{
Low- and high-level controlled processing in executive motor control tasks in 5-6-year-old children at risk of ADHD
}

\author{
Ariane C. Kalff, ${ }^{1}$ Leo M.J. de Sonneville ${ }^{2}$ Petra P.M. Hurks, ${ }^{1}$ Jos G.M. \\ Hendriksen, ${ }^{3}$ Marielle Kroes, ${ }^{3}$ Frans J.M. Feron, ${ }^{6}$ Jean Steyaert, ${ }^{4}$ \\ Thea M.C.B. van Zeben, ${ }^{5}{ }^{3}$ ohan S.H. Vles, ${ }^{3}$ and Jelle Jolles ${ }^{1}$
}

\begin{abstract}
${ }^{1}$ Department of Psychiatry and Neuropsychology, University of Maastricht, The Netherlands; ${ }^{2}$ Vrije UniversiteitMedical Centre of Amsterdam, The Netherlands; ${ }^{3}$ Department of Neurology, ${ }^{4}$ Department of Psychiatry, ${ }^{5}$ Department of Pediatrics, University Hospital of Maastricht, The Netherlands; ${ }^{6}$ Youth Health Care of the Municipal Health Centre, Maastricht, The Netherlands
\end{abstract}

\begin{abstract}
Background: The scant research on the characteristics of Attention-Deficit/Hyperactivity Disorder (ADHD) in kindergarten years curtails progress on early assessment of ADHD. Method: By screening a general population sample of 1317 five- to six-year-old children, four groups of children were selected. The performance of 30 children later diagnosed with ADHD was compared with 74 children later diagnosed with 'borderline ADHD' (children exhibiting all ADHD symptoms but without disruptions on two situations), 113 children later diagnosed with other psychopathology, and 126 healthy controls on computerised motor control tasks involving low- and high-level controlled processing. In addition, motor control was compared with movement speed. Results: The children at risk of ADHD were in general less accurate and more variable in their movements than the children with other psychopathology and healthy controls. Under conditions of high-level controlled processing, the children at risk of ADHD were disproportionately more inaccurate and had a more unstable performance with their preferred hand than the other children. In addition, linear effects were found, with the children at risk of ADHD having the worst performance, followed by the children with 'borderline ADHD', and then both groups of control children. No significant group differences were found in movement speed. Conclusions: The main findings are interpreted as evidence for a specific deficit in high-level controlled processing in young children at risk of ADHD, now found in a motor task, rather than a response task. Furthermore, the results support the notion that ADHD represents a dimensional trait. In addition, problems in movement control (the need to allocate attentional capacity) rather than problems in movement speed distinguish children at risk of ADHD from other children. The findings are interpreted as evidence that higher-order executive processes, such as self-control and self-regulation, are already affected early in the development of ADHD. Keywords: ADHD, information processing, motor control tasks, risk factors. Abbreviations: ADIKA: Amsterdam Diagnostic Interview for Children and Adolescents; ANT: Amsterdam Neuropsychological Tasks; SAM: Study of Attention disorders in Maastricht.
\end{abstract}

Attention-Deficit/Hyperactivity Disorder (ADHD) is the most commonly diagnosed psychiatric disorder of childhood, affecting approximately $3-5 \%$ of the school-age population, and carries a potentially poor prognosis (American Psychiatric Association, 1994; Barkley, 1998; Stubbe, 2000). It is characterised by developmentally inappropriate and persistent symptoms of inattention, hyperactivity, and impulsivity. Several deficits that may contribute to the behavioural pattern of ADHD have been suggested, such as an attention deficit (Douglas, 1972), a motor control deficit (Van der Meere, Van Baal, \& Sergeant, 1989), a working memory impairment, delay aversion, or a deficit in executive functions, in particular the response inhibition and self-regulation that control subordinate cognitive processes (Barkley, 1997; Kuntsi, Oosterlaan, \& Stevenson, 2001).

It is difficult to draw straightforward conclusions about which deficit is primary because investigators have often used a wide range of tests that make demands on various aspects of perceptual, motor, and cognitive performance. For example, deficits in motor control in ADHD have been reported especially when more complex motor sequences have to be performed, which suggests that higher-order cognitive processes, such as planning and behavioural programming, organisation in memory, and selfregulation, are involved (Barkley, 1998, p. 119). Indeed, Leung and Connolly (1998) found that neither motor organisation nor motor execution was impaired in ADHD in a study in which they tried to unravel the nature of the motor deficits by examining the organisation and execution of motor sequences in a simple sequential tapping task. They suggested that more complex motor tasks, which make demands on higher-order cognitive processing, should be used when trying to identify impairments in ADHD.

Higher-order cognitive processes, which are also referred to as effortful or controlled processes (Hasher \& Zacks, 1979), require continuous attention capacity and are often opposed to automatic 
processes, which can be innate or acquired with practice and are not affected by attention capacity (Schneider \& Shiffrin, 1977). While no evidence was found for deficits in acquired automatic processing (Van der Meere \& Sergeant, 1988), most studies have demonstrated deficits in controlled processing in school-aged children with ADHD (Borcherding et al., 1988; De Sonneville, Njiokiktjen, \& Bos, 1994; Nigg, Hinshaw, Carte, \& Treuting, 1998). However, a recent study did not find support for a deficit in controlled processing in children with ADHD (Hazell et al., 1999).

Most studies on ADHD have involved only schoolaged children and there is little information on the characteristics of ADHD in younger children (Mariani \& Barkley, 1997). It is not clear whether deficits are already evident in children younger than 7 years. Moreover, it is difficult to establish a diagnosis of ADHD in young children because many symptoms of ADHD are transient (Marakovitz \& Campbell, 1998). Thus, knowledge of the cognitive and motor characteristics of young children at risk of ADHD gained from longitudinal studies may contribute to more accurate and stable diagnoses at young ages.

The main goal of the present study was to compare the performance of 5-6-year-old children at risk of ADHD on two computerised complex motor control tasks (the Tracking task and the Pursuit task; see Method) that have proven suitable for use with young children (De Sonneville, Visser, \& Licht, 1999). In motor function, the match between intended and realised movements is usually achieved automatically (Jeannerod, 1997). The dorsolateral prefrontal cortex (PFC) mediates cross-temporal contingencies between perception and movement (Fink et al., 1999; Fuster, 2000; Seitz, Stephan, \& Binkofski, 2000), and integration by the PFC of perception and action is especially required in novel or complex situations that necessitate conscious control of action and awareness of sensory feedback (Wolpert, Ghahramani, \& Jordan 1995). The Tracking task involves the drawing of a circle, a wellpractised figure that can be planned in advance, requiring a low level of controlled processing. The Pursuit task involves the close pursuit of a target that moves continuously and in random directions, necessitating concurrent execution and adjustment of continuously changing movements, and imposes more controlled processing demands. In light of the above and the well-established close interaction of motor control capacities and executive functioning (Diamond, 2000), we take the position that the necessary continuous monitoring of task performance during execution of these tasks imposes important executive function demands. This has recently been confirmed in a study with children with phenylketonuria, who have been regularly reported to exhibit executive function deficits associated with PFCdysfunction (Diamond, Prevor, Callender, \& Druin, 1997). They showed lower task performance levels on these tasks, and the amount of continuous monitoring required was reflected in the extent of the deficits (Huijbregts et al., 2002; Huijbregts et al., in press). Additionally, a simple test of movement speed was used to compare with the complex motor control tasks in order to determine whether particularly specific deficits in motor control underlie ADHD.

The performance of 5-6-year-old children diagnosed with ADHD at follow-up was compared not only with that of healthy control children, but also with that of children with psychopathology other than ADHD (referred to as pathological control children). This was done in order to evaluate the specificity of the results. In addition, a group of children with so-called 'borderline ADHD' (children exhibited ADHD symptoms but these symptoms did not lead to disruptions in at least two situations) was included to examine whether ADHD can be conceptualised as a dimensional trait expressed as qualitative differences between individuals.

\section{Method}

This report is part of a large research program entitled Study of Attention Disorders in Maastricht (SAM), involving a prospective cohort study of 5- and 6-year-old children in the south of the province of Limburg, the Netherlands (Kalff et al., 2001; Kroes et al., 2001). The study was approved by the local Medical Ethics Committee. The study was performed in three phases (see below).

\section{Subjects and procedure}

Phase 1 (selection). The initial sample comprised 2290 children in the second grade of a normal kindergarten who visited the Youth Health Care (YHC) for a periodic health examination, of which 1317 (57.5\%; 699 boys and 618 girls, mean age 5.87 (SD .41)) were granted permission by their parents to participate. Subsequently, parents were asked to complete the Dutch version of the Child Behavior Checklist (CBCL; Verhulst, Koot, \& van der Ende, 1996). Responders and non-responders were compared for child characteristics (sex, age, and birth weight), Apgar score, pregnancy-related problems, psychosocial/physical findings reported by the school doctor), family factors (parental occupation, family status, country of birth of parents, number of children and sibship position, illness of parents), and environmental factors (urban or rural living area and school) by randomly sampling 200 subjects in each group (for a full description, see Kroes et al., 2001). The information was obtained anonymously from the medical records of the YHC, which is allowed by law for epidemiological research purposes. No significant differences were found between the groups.

On the basis of the CBCL scores, three groups of children (in total $N=452$ ) were selected for the second phase. The first group consisted of children with scores above the 90th percentile on the Externalising scale and/or scores above the 95th percentile on the subscale Attention Problem (Group I; $N=173$ ). This group 
contained children with a putative risk for a later diagnosis of ADHD (Chen, Faraone, Biederman, \& Tsuang, 1994). The second group consisted of children with scores above the 90th percentile on the Internalising scale and who were not members of group I (Group II; $N=59$ ). Group II was included to investigate children at risk of other psychopathology. Children with clinical scores on Internalising and Externalising scales were assigned to group I. The third group, matched for age ( \pm 2 months), sex, and school with children of groups I and II, consisted of children with Total problem scores below the 90th percentile (Group III; $N=220$ ).

Phase 2 (assessment). Four months after selection, neurocognitive tasks were administered to 400 of the 452 children. Nine children no longer participated in the study and 43 children could not be assessed for logistical reasons; for example, because there was not enough school time or space available to assess the children. The assessment was carried out by one of ten well-trained psychologists who were blind to the group assignments and took place in a separate room at the children's school.

Phase 3 (follow-up diagnosis). One and a half years after selection, 403 parents of the original 452 selected children were interviewed using the Dutch version of the Diagnostic Interview for Children and Adolescents (DICA; Herjanic \& Reich, 1982; ADIKA; Kortenbout van der Sluijs, Levita, Manen, \& Defares, 1993). Eleven percent of the parents $(N=49)$ refused further participation or had moved. The interviews were conducted by three interviewers who were trained and supervised by a senior child psychiatrist and who were blind to group membership. The ADIKA was adapted, using the criteria of DSM IV, to make it suitable for ADHD classification (Van Grimbergen, Célestin-Westreich, \& Ponjaert-Kristofferson, 1999).

For the present study, complete neurocognitive and ADIKA data were available for 343 children $(76 \%$ of the original selected sample). There were no significant differences between the children who were included or excluded in the analyses in terms of sex, CBCL selection groups, and parental occupation. The groups differed significantly only with regard to their age, the participating group being younger $\left(F_{1,450}=12.37, p<.000\right)$. Four groups of children were identified: (1) children who met the diagnostic criteria for ADHD at follow-up, hereafter called ADHD $(N=30)$; (2) children who met the diagnostic criteria for ADHD at a later age but whose symptoms did not lead to disruption in at least two situations $(55 \%$ showed impairments in one situation and $45 \%$ did not show impairments of their symptoms at all), hereafter called 'borderline ADHD' $(N=74)$; (3) children who met at least one of the DSMIII-R criteria (American Psychiatric Association, 1987) for oppositional defiant disorder, conduct disorder, anxiety disorders, mood disorders, obsessive compulsive disorder, Asperger's disorder, or disorders of elimination at a later age but without ADHD, hereafter called pathological controls $(N=113)$; and (4) children who had no psychiatric disorder, hereafter called healthy controls $(N=126)$. Comorbidity with other psychiatric disorders in the ADHD and borderline ADHD' groups was allowed because this appears to be the rule rather than the exception in children with ADHD (Kadesjö \& Gillberg, 2001). Because of the diversity of the comorbid disorders, the different diagnoses were included in the pathological control group.

Group characteristics are shown in Table 1. There were significant differences in estimated IQ, level of parental occupation, and sex. Also, the CBCL groups were disproportionately distributed with regard to the ADIKA classification. Hand preference was simply ascertained by asking the child which hand was used when making a drawing. Next, the child was handed a pencil to check whether the child indeed used that hand. Hand preference was equally distributed between the groups.

\section{Intelligence screening measure and parental occupation}

Intellectual functioning was estimated using the Vocabulary subtest from the Revised Amsterdam Child Intelligence Test (RAKIT; Bleichrodt, Drenth, Zaal, \& Resing, 1987). This subtest measures the verbal ability of the child and is similar to the well-known Peabody Picture Vocabulary Test, which is considered to give a valid approximation of IQ (Marakovitz \& Campbell, 1998).

The Level of Occupational Achievement (LOA) of the parents was scored on a 7-point scale based on the mental complexity of the work, as rated by job experts

Table 1 Descriptive data of the diagnostic groups

\begin{tabular}{|c|c|c|c|c|c|c|c|c|c|c|}
\hline & \multicolumn{2}{|c|}{$\begin{array}{l}\text { (1) ADHD } \\
(N=30)\end{array}$} & \multicolumn{2}{|c|}{$\begin{array}{l}\text { (2) 'Borderline } \\
\text { ADHD' }(N=74)\end{array}$} & \multicolumn{2}{|c|}{$\begin{array}{l}\text { (3) Pathological } \\
\text { controls } \\
(N=113)\end{array}$} & \multicolumn{2}{|c|}{$\begin{array}{l}\text { (4) Healthy } \\
\text { controls } \\
(N=126)\end{array}$} & \multirow[b]{2}{*}{$F$} & \multirow[b]{2}{*}{$p^{\mathrm{a}}$} \\
\hline & mean & $\mathrm{sd}$ & mean & $\mathrm{sd}$ & mean & sd & mean & $\mathrm{sd}$ & & \\
\hline Age (in years) & 6.17 & .34 & 6.25 & .55 & 6.15 & .44 & 6.22 & .44 & .87 & .46 \\
\hline Estimated $\mathrm{IQ}^{\mathrm{b}}$ & 90.37 & 19.53 & 88.49 & 21.36 & 98.62 & 22.16 & 94.21 & 24.46 & 3.28 & $.02^{2,3}$ \\
\hline LOA & 3.31 & 2.09 & 3.69 & 1.94 & 3.82 & 2.04 & 4.50 & 1.79 & 4.83 & $.00^{1,2,3,4}$ \\
\hline $\operatorname{Sex}(m / f)$ & \multicolumn{2}{|c|}{$23 / 7$} & \multicolumn{2}{|c|}{$49 / 25$} & \multicolumn{2}{|c|}{$64 / 49$} & \multicolumn{2}{|c|}{$58 / 68$} & 13.43 & $.00^{\mathrm{c}}$ \\
\hline $\mathrm{CBCL}(\mathrm{E} / \mathrm{I} / \mathrm{C})$ & \multicolumn{2}{|c|}{$28 / 1 / 1$} & \multicolumn{2}{|c|}{$47 / 7 / 20$} & \multicolumn{2}{|c|}{$42 / 24 / 47$} & \multicolumn{2}{|c|}{$16 / 12 / 98$} & 110.07 & $.00^{\mathrm{c}}$ \\
\hline Handpref. (r/l) & \multicolumn{2}{|c|}{$28 / 2$} & \multicolumn{2}{|c|}{$65 / 9$} & \multicolumn{2}{|c|}{$103 / 10$} & \multicolumn{2}{|c|}{$110 / 16$} & 1.59 & $.66^{\mathrm{c}}$ \\
\hline
\end{tabular}

Note: LOA: = Level of Occupational Achievement of parents scored on 7-point scale; CBCL = Child Behavior Checklist groups: $\mathrm{E}=$ Externalising, $\mathrm{I}=$ Internalising, $\mathrm{C}=$ Controls; Handpref. $\mathrm{r} / 1=$ hand preference right or left.

${ }^{a}$ Post hoc Tukey's HSD, $p<.05 ;{ }^{\text {b }}$ Estimated intelligence screening measure (mean $=100$, sd $=15$ ); ${ }^{\mathrm{c}}$ Chi-square test. 
(DGA, 1989). The scale ranges from unskilled to academic labour. For children living with both parents, the highest level was used; for the remaining children, the level of the parent with whom the child lived was used.

\section{Dependent measures}

The Tracking task of the computerised test battery Amsterdam Neuropsychological Tasks (ANT; De Sonneville, 1999) requires the child to trace the mouse cursor in between a fixed outer and inner circle presented on the computer display (see Figure 1, left): once with the right hand (the cursor being moved in clockwise direction) and once with the left hand (the cursor being moved in counter-clockwise direction). The program divides the trajectory into 60 radially equal segments and computes the mean distance between the cursor trajectory and the (invisible) midline per segment, resulting in 60 deviation scores. The total mean distance and the within-subjects variability of the mean distance for each hand were used as dependent measures for the accuracy of movement and stability of movement, respectively. In addition, the total time to complete the task with each hand was recorded in seconds and used as dependent measure as an index for movement speed.

The Pursuit task of the ANT requires the child to follow a target (an asterisk) that randomly moves across the computer screen as closely as possible with the mouse cursor (see Figure 1, right). The task has to be executed with each hand lasting 60 seconds. The program computes the mean distance between the mouse cursor and the moving target per second, resulting in 60 deviation scores. The total mean distance and the within-subjects variability of the mean distance for each hand are used as dependent measures for the accuracy of movement and stability of movement, respectively.

The Purdue Pegboard (Tiffin, 1968) measures simple movement speed. The child is required to place pegs in holes as fast as possible using the dominant hand, then the non-dominant hand, followed by both hands together. Each trial lasts 30 seconds. The numbers of pegs placed correctly with each hand and both hands are used as dependent variables as an index for movement speed.

\section{Statistical analyses}

Task performance in the four diagnostic groups (ADHD, 'borderline ADHD', pathological controls, healthy controls) was analysed using a $4 \times 2$ (group $\times$ task) GLM repeated measures design with separate runs for each hand and each dependent measure. Task performance was analysed separately for the preferred and the non-preferred hands because of the young age of the children. Hand preference is not established until approximately age six (Bryden, Pryde, \& Roy, 2000), and an earlier study of normal young children showed differences in performance in favour of the dominant hand (De Sonneville et al., 1999). Separate runs for mean distance and within-subject variability were performed to avoid high correlations between the dependent variables. The Geiser Greenhouse corrected probabilities were used to deal with unequal sample sizes. Planned comparisons with the simple contrast were used to compare each of the groups with the ADHD group. The Group $\times$ Task interaction reflects the extent to which differences between groups are task dependent. Second repeated measures analyses were used with polynomial contrasts to examine the linear effect across the group classifications. That is, to examine whether the groups can be arranged on a continuum. The movement speed measures (total time on the Tracking task and the number of placed pegs in the Purdue Pegboard) were analysed in multivariate analyses of variance for each hand separately. Both hands on the Purdue Pegboard were analysed in univariate analyses of variance.

All analyses were conducted with and without IQ and parental occupation as covariates. Although sex is also suspected to correlate with ADHD, sex was not entered as a covariate because univariate $F$-tests indicated that

\section{Tracking task}

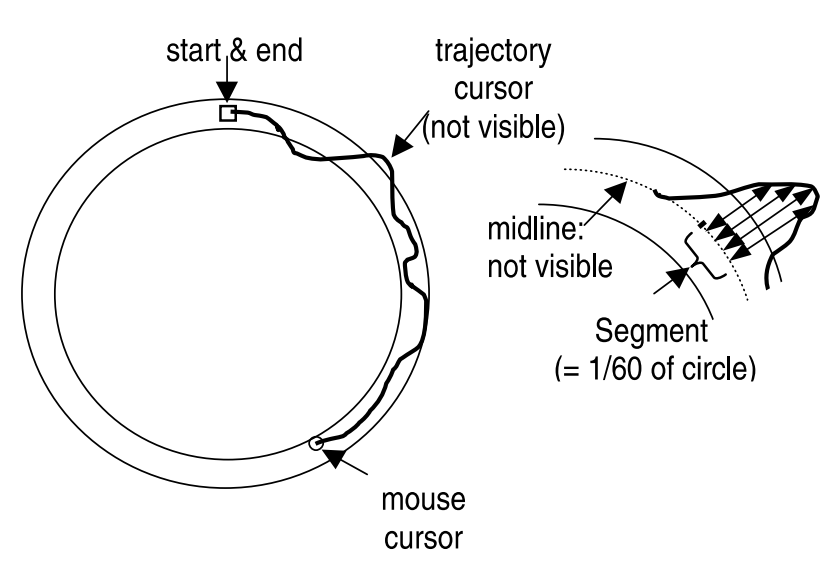

\section{Pursuit task}

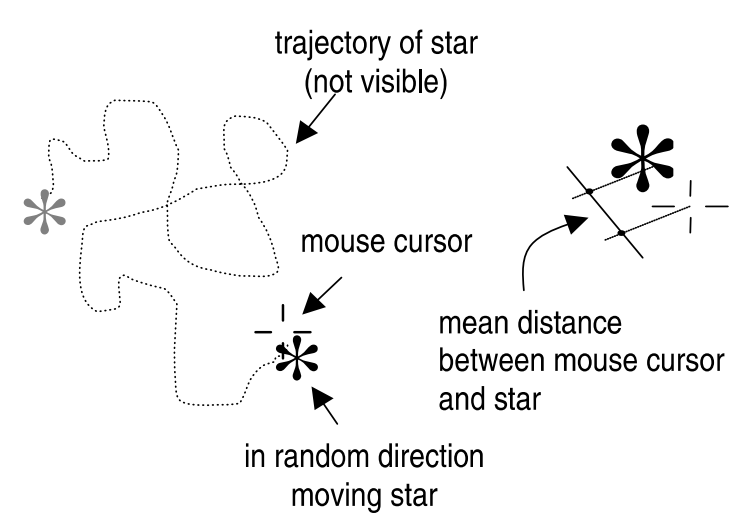

Figure 1 Design Tracking task and Pursuit task: An example of the signal and subject (cursor) trajectory of the tracking task is presented on the left. Mean distance between cursor and midline per segment gives 60 deviation scores. An example of the random target trajectory of the Pursuit task is presented on the right. Mean distance between cursor and star per second task time gives 60 deviation scores 
there were no significant differences between boys and girls in the healthy control group on all measures except for the two movement speed measures: girls being slower than boys on the Tracking task and boys placing fewer pegs than girls in the Purdue Pegboard. In these 'speed' analyses, sex was entered as covariate. All data were analysed using SPSS 10.0.

\section{Results}

Five children were excluded from the analyses because their data for mean distance and within-subjects variability of the Tracking and Pursuit tasks were outliers on multivariate analysis (greater than 3 $\mathrm{SD}$ above or below the mean). These children were equally distributed across the diagnostic groups. As all results with and without covariates were essentially the same, only the data without IQ and parental occupation as covariates are presented.

Figure 2 shows the mean distance (two left panels) and within-subjects variability (two right panels) for the diagnostic groups in the Tracking and Pursuit tasks for each hand separately. The repeated measures analyses revealed significant main effects of group on the mean distance (left panels) for the preferred hand $\left(F_{3,325}=8.37, p<.001\right)$ as well as for the non-preferred hand $\left(F_{3,316}=4.00, p=.008\right)$. Thus, the groups differed in terms of the accuracy of movements made with both hands. With the preferred hand, the responses of the children at risk of ADHD were less accurate than those of all other groups (simple contrasts: $p=.004, p<.001$, and $p<.001$ compared to the 'borderline ADHD', pathological controls, and healthy controls, respectively). With the non-preferred hand, the children at risk of ADHD were only less accurate than the healthy controls $(p=.008)$.

A significant Group $\times$ Task interaction was found for the preferred hand $\left(F_{3,325}=4.86, p=.003\right)$ but not for the non-preferred hand $\left(F_{3,316}=.60\right.$, $p=.616)$. Thus, the group differences depended on the task performed but only when the preferred hand was used, with the children at risk of ADHD being more inaccurate on the Pursuit task than on the Tracking task compared with the children from the other groups. The second repeated measure analysis to examine whether there was a linear effect between the groups yielded a significant polynomial contrast for the preferred and non-preferred hands $(p<.001$ and $p=.003$, respectively), indicating a linear effect in accuracy, with children at risk of ADHD being the least accurate and healthy controls being the most accurate.

Similar results were found for the within-subjects variability (see Figure 2, right panels). The main group effects were significant for both the preferred hand $\left(F_{3,334}=8.76, p<.001\right)$ and the non-preferred hand $\left(F_{3,334}=5.24, p=.002\right)$. Thus, the groups differed in the stability of movement with both hands. With the preferred hand, the children at risk of ADHD had a more variable response than the other children $(p=.009, p<.001$, and $p<.001$ for the 'borderline ADHD', pathological controls, and healthy controls comparisons, respectively). However, with the non-preferred hand, the children at risk of ADHD only had a more variable response than the healthy controls $(p=.019)$.

The two-way interaction Group $\times$ Task was significant for the preferred hand $\left(F_{3,334}=4.06\right.$, $p=.007)$ but not for the non-preferred hand $\left(F_{3,334}=.12, p=.951\right)$. Again, this shows that group differences depended on the task performed only when the preferred hand was used, with differences between ADHD and the other groups being much greater on the Pursuit task than on the Tracking task. The polynomial contrast in the second repeated measure analysis was significant for the preferred and non-preferred hands $(p<.001$ and $p=.006$,

\section{preferred hand non-preferred hand}

preferred hand

- ADHD, $\square$ 'borderline ADHD', • pathological controls, $\bigcirc$ controls
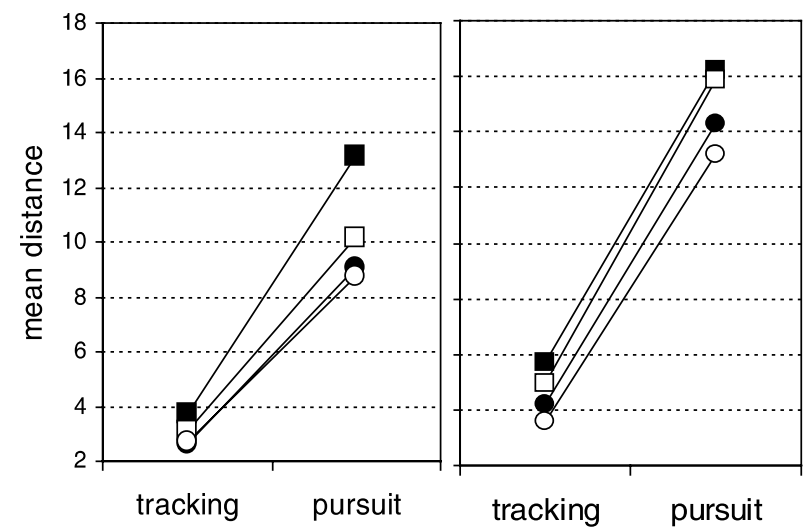
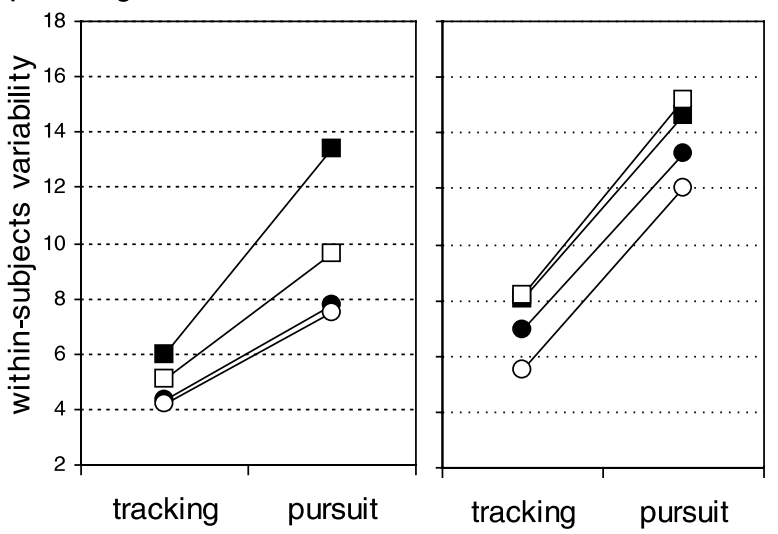

Figure 2 Mean distance (left panels) and within-subjects variability (right panels) in Tracking and Pursuit tasks, separately for preferred and non-preferred hand in the ADHD group, 'borderline ADHD' group, pathological controls, and healthy controls 
Tracking

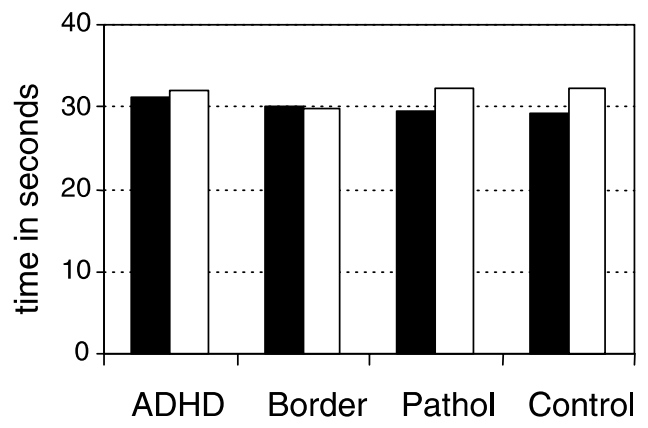

Purdue Pegboard

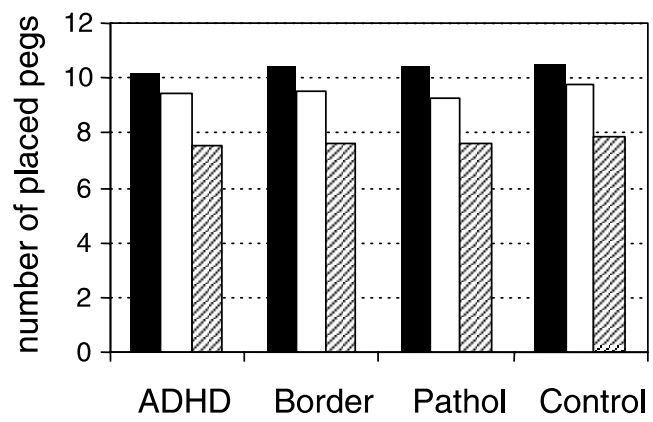

Figure 3 Measures of movement speed for the preferred hand (black bars), non-preferred hand (white bars), and both hands on the Purdue Pegboard (grey bars)

respectively), indicating a linear effect on the stability of movement, with children at risk of ADHD showing the most variability and healthy controls showing the least variability.

Figure 3 shows the results for the movement speed measures: total time on the Tracking task and the number of placed pegs on the Purdue Pegboard. No significant differences in movement speed were found between the groups for the preferred hand and the non-preferred hand on both tasks. In addition, no significant differences were found between the groups for both hands on the Purdue Pegboard test.

\section{Discussion}

The present study was designed to examine the performance of young children at risk of ADHD on two complex motor control tasks that differed in their level of cognitive processing: the Tracking task requires low levels of controlled processing and the Pursuit task demands high levels of controlled processing. The children at risk of ADHD were compared with pathological control children, healthy control children, and children at risk of 'borderline ADHD'. Results showed that 5-6-year-old children who were later diagnosed with ADHD were less accurate and more variable in their movements with both the preferred and the non-preferred hand on both tasks than the children later diagnosed with other or no pathology. Thus, in general, inaccuracy and instability of the movement pattern are found in ADHD but not in other psychopathologies, which demonstrates the specificity of the results.

Interestingly, children at risk of ADHD were disproportionately more inaccurate and had more variable movement patterns on the Pursuit task, which involves high-level controlled processing, than on the Tracking task, which involves low-level controlled processing, when using their preferred hand. Thus, young children at risk of ADHD have a more pronounced deficit in movement patterns when task demands are high, demonstrating a specific deficit in higher-order controlled processes in these children.
The current findings corroborate those of most studies of school-aged children with ADHD (Borcherding et al., 1988; De Sonneville et al., 1994; Nigg et al., 1998), but are new in that the finding has now been replicated in a motor task, rather than a response task. Also, our results concern younger children at risk of ADHD and yield information on cognitive and motor processing in an early stage of ADHD. The results indicate that higher-order executive processes, such as the ability to monitor, self-correction, and self-regulation, are already affected early in the development of ADHD.

The failure to find disproportionately poorer results for the non-preferred hand may be because the children in our study were relatively young. Before the age of 6 , hand preference is not yet established in most children (Bryden et al., 2000) and the nonpreferred hand may be unpractised. Indeed, a recent study showed that children aged 6 to 10 years overuse their preferred hand (Pryde, Bryden, \& Roy, 2000). Consequently, every task with the non-preferred hand will require continuous attention, which may attenuate or even counteract the assumed contrast in low- versus high-level controlled processing of the two motor control tasks. In other words, both tasks probably involve highly controlled processing when performed with the non-preferred hand in all groups of children aged 5 to 6 years.

Our results showed a linear effect in the accuracy and stability of movements across all groups, with ADHD at one extreme, followed by 'borderline ADHD', pathological controls, and finally healthy controls at the other. These results may support the presence of sub-syndromal ADHD, but on the other hand, the performance decline across the groups also supports the view that ADHD is a dimensional trait rather than a pathological category (Barkley, 1998 , p. 73). Defects in the control of complex perceptual-motor functions that are characteristics of ADHD occur over a continuum across the normal population. Categorical diagnoses are increasingly felt to be at variance with reality. The notion of a continuum has already been formulated with respect to other neurodevelopmental disorders (Bax, 1999), 
such as dyslexia (Shaywitz, Escobar, Shaywitz, Fletcher, \& Makuch, 1992). Moreover, the intermediate position of the children with 'borderline ADHD' is interesting in this respect, because the children at risk of ADHD and 'borderline ADHD' were equally symptomatic but differed in that the ADHD symptoms in the latter group did not lead to disruptions in at least two situations, a requirement for the diagnosis of ADHD according to DSM-IV (American Psychiatric Association, 1994). Schachar, Tannock, Marriott, and Logan (1995) reported that it is possible for children to exhibit symptoms of ADHD without having an inhibitory deficit. Our results, on the other hand, demonstrate that apparently the symptoms themselves are associated with a poor performance. The study design, however, does not permit us to draw conclusions about the causality.

The groups of children were not different in terms of movement speed, whereas they were in terms of motor control. These results are consistent with the literature on school-age children with ADHD (Leung \& Connolly, 1998; Piek, Pitcher, \& Hay, 1999; Steger et al., 2001). Our results demonstrate that these findings can be extended to even younger children aged 5-6 years. Apparently, it is not the quantitative aspect of a movement (namely, movement speed) but the qualitative aspect (namely, how controlled the movement is or how attentional capacity can be appropriately allocated) that distinguishes children at risk of ADHD from other children. This was also suggested by Kroes et al. (2002), who found that qualitative aspects of all motor domains were predictive of ADHD. Children with ADHD appear to have problems with controlling the pattern of motor movements, which is in line with the self-regulation theory of Barkley (1997). According to this theory, a deficit in self-control or behavioural inhibition is the underlying deficit of ADHD.

Several limitations of the present study need to be considered. First, the relatively low response rate (57.5\% of the initial sample) and the exclusion of selected children in the analyses $(24 \%$ of the selected sample) may limit the extent to which the results can be generalised to the population. However, a prospective design was used and there were no significant differences between a subgroup of responders and non-responders. Second, the psychiatric diagnoses were based on the criteria of the ADIKA. Although the reliability and validity of the original interview are reported to be good (Reich, 2000), no reliability studies have been performed for the Dutch version of this diagnostic interview. Moreover, multiple informants were not used because the ADIKA only makes use of information provided by the parents. This may have led to over-inclusiveness. On the other hand, there is evidence of a $90 \%$ overlap between parent reports and teacher reports (Barkley, 1998, p. 69).

In conclusion, the present study demonstrated a disproportionately worse performance in terms of accuracy and stability of movements when task demands are high in 5-6-year-old children at risk of ADHD than in children suffering from other forms of pathology and healthy controls. This can be explained by a specific deficit in high-level controlled processing, in addition to a general poor performance on motor control tasks, which involve low-level controlled processing. The lack of differences in movement speed between the groups of children supports the view that qualitative aspects of movement are affected in ADHD. Thus, deficits in self-control and self-regulation already seem to be present early in the development of ADHD, and these deficits cause problems in several domains.

\section{Acknowledgements}

This study was supported by the Brain \& Behavior Research Institute of University of Maastricht; the University Hospital of Maastricht fund for outstanding and competitive clinical research (the 'Profileringsfonds'); the Prevention Foundation of the Netherlands; and the St-Clemens and Kan.Salden Foundations of the Netherlands.

\section{Correspondence to}

Ariane Kalff, c/o Academic Department of Neuropsychology, PMS Vijverdal P.O. Box 88, 6200 AB, Maastricht, the Netherlands; Email: tjeenk@tip.nl

\section{References}

American Psychiatric Association. (1987). Diagnostic and statistical manual of mental disorders (3rd edition-revised). Washington, DC: American Psychiatric Press.

American Psychiatric Association. (1994). Diagnostic and statistical manual of mental disorders (4th edition). Washington, DC: American Psychiatric Press.

Barkley, R.A. (1997). Behavioral inhibition, sustained attention, and executive functions: Constructing a unifying theory of ADHD. Psychological Bulletin, 121, 65-94.

Barkley, R.A. (1998). Attention deficit hyperactivity disorder. A handbook for diagnosis and treatment (2nd edn). New York: The Guilford Press.

Bax, M. (1999). Specific learning disorders/neurodevelopmental disorders. Developmental Medicine and Child Neurology, 41, 147.

Bleichrodt, N., Drenth, P.J.D., Zaal, J.N., \& Resing, W.C.M. (1987). RAKIT: Handleiding bij de Revisie Amsterdamse Kinder Intelligentie Test [Manual of the revised Amsterdam intelligence test for children]. Lisse, the Netherlands: Swets \& Zeitlinger.

Borcherding, B., Thompson, K., Kruesi, M., Bartko, J., Rapoport, J.L., \& Weingartner, H. (1988). Automatic and effortful processing in attention deficit/hyperactivity disorder. Journal of Abnormal Child Psychology, $16,333-345$. 
Bryden, P.J., Pryde, K.M., \& Roy, E.A. (2000). A developmental analysis of the relationship between hand preference and performance: II. A performancebased method of measuring hand preference in children. Brain and Cognition, 43, 60-64.

Chen, W.J., Faraone, S.V., Biederman, J., \& Tsuang, M.T. (1994). Diagnostic accuracy of the Child Behavior Checklist scales for attention-deficit hyperactivity disorder: A receiver-operating characteristic analysis. Journal of Consulting and Clinical Psychology, 62, 1017-1025.

De Sonneville, L.M.J. (1999). Amsterdam Neuropsychological Tasks: A computer-aided assessment program. In B.P.L.M. Den Brinker, P.J. Beek, A.N. Brand, S.J. Maarse, \& L.J.M. Mulder (Eds.), Cognitive ergonomics, clinical assessment and computer-assisted learning: Computers in psychology (vol. 6, pp. 187-203). Lisse, the Netherlands: Swets \& Zeitlinger.

De Sonneville, L.M.J., Njiokiktjen, C., \& Bos, H. (1994). Methylphenidate and information processing: I. Differentiation between responders and nonresponders: II. Efficacy in responders. Journal of Clinical and Experimental Neuropsychology, 16, 877-897.

De Sonneville, L.M.J., Visser, M., \& Licht, R. (1999). Attention and information processing in 4- and 5year-old children: Results of a computerized assessment technique. In B.P.L.M. Den Brinker, P.J. Beek, A.N. Brand, S.J. Maarse, \& L.J.M. Mulder (Eds.), Cognitive ergonomics, clinical assessment and computer-assisted learning: Computers in psychology (vol. 6, pp. 204-217). Lisse, the Netherlands: Swets \& Zeitlinger.

Diamond, A. (2000). Close interrelation of motor development and cognitive development and of the cerebellum and prefrontal cortex. Child Development, 71, 44-56.

Diamond, A., Prevor, M.B., Callender, G., \& Druin, D.P. (1997). Prefrontal cortex cognitive deficits in children treated early and continuously for PKU. Monographs of the Society for Research in Child Development, 62, $1-208$.

Directoraat-Generaal voor de Arbeidsvoorziening (DGA). (1989). Handleiding voor de functieanalyse [Manual functional analysis]. The Hague, the Netherlands: SDU Uitgeverij.

Douglas, V.I. (1972). Stop, look, and listen: The problem of sustained attention and impulse control in hyperactive and normal children. Canadian Journal of Behavioural Science, 4, 259-282.

Fink, G.R., Marshall, J.C., Halligan, P.W., Frith, C.D., Driver, J., Frackowiak, R.S.J., \& Dolan, R.J. (1999). The neural consequences of conflict between intention and the senses. Brain, 122, 497-512.

Fuster, J.M. (2000). (Proceedings of the human cerebral cortex: From gene to structure and function). Prefrontal neurons in networks of executive memory. Brain Research Bulletin, 52, 331-336.

Hasher, L., \& Zacks, R.T. (1979). Automatic and effortful processes in memory. Journal of Experimental Psychology: General, 108, 356-388.

Hazell, P.L., Carr, V.J., Lewin, T.J., Dewis, S.A., Heathcote, D.M., \& Brucki, B.M. (1999). Effortful and automatic information processing in boys with ADHD and specific learning disorders. Journal of Child Psychology and Psychiatry, 40, 275-286.
Herjanic, B., \& Reich, W. (1982). Development of a structured psychiatric interview for children: Agreement between child and parent in individual symptoms. Journal of Abnormal Child Psychology, 10, 307-324.

Huijbregts, S.C.J., De Sonneville, L.M.J., Van Spronsen, F.J., Berends, I.E., Licht, R., Verkerk, P.H., \& Sergeant, J.A. (in press). Executive motor control under lower and higher controlled processing demands in early- and continuously treated phenylketonuria. Neuropsychology.

Huijbregts, S.C.J., De Sonneville, L.M.J., Van Spronsen, F.J., Berends, I.E., Licht, R., Verkerk, P.H., \& Sergeant, J.A. (2002). Motor function under lower and higher controlled processing demands in earlyand continuously treated phenylketonuria. Developmental Neuropsychology, 22, 481-499.

Jeannerod, M. (1997). The cognitive neuropsychology of action. Oxford: Blackwell.

Kadesjö, B., \& Gillberg, C. (2001). The comorbidity of ADHD in the general population of Swedish schoolage children. Journal of Child Psychology and Psychiatry, 42, 487-492.

Kalff, A.C., Kroes, M., Vles, J.S.H., Bosma, H., Feron, F.J.M., Hendriksen, J.G.M., Steyeart, J., van Zeben, T.M.C.B., Crolla, I.F.A.M., \& Jolles, J. (2001). Factors affecting the relationship between parental education as well as occupation and problem behavior in Dutch 5-to-6-year-old children. Social Psychiatry and Psychiatric Epidemiology, 36, 324-331.

Kortenbout van der Sluijs, M.J., Levita, D.J., Manen, R., \& Defares, P.B. (1993). Amsterdam Diagnostisch Interview voor Kinderen en Adolescenten (ADIKA) [Amsterdam Diagnostic Interview for Children and Adolescents]. Lisse, the Netherlands: Swets \& Zeitlinger.

Kroes, M., Kalff, A.C., Steyaert, J., Kessels, A.G.H., Feron, F.J.M., van Someren, A.J.W.G.M., Hurks, P.P.M., Hendriksen, J.G.M., van Zeben, T.M.C.B., Rozendaal, N., Crolla, I.F.A.M., Jolles, J., Troost, J., \& Vles, J.S.H. (2001). Child psychiatric diagnoses generalized to a population of Dutch school children aged 6 to 8 years. Journal of the American Academy of Child and Adolescent Psychiatry, 40, 1401-1409.

Kroes, M., Kessels, A.G.H., Kalff, A.C., Feron, F.J.M., Vissers, F.J.M., Jolles, J., \& Vles, J.S.H. (2002). Quality of movement as predictor of ADHD: Results from a prospective population study in 5- and 6-yearold children. Developmental Medicine and Child Neurology, 44, 753-760.

Kuntsi, J., Oosterlaan, J., \& Stevenson, J. (2001). Psychological mechanism in hyperactivity: I Response inhibition deficit, working memory impairment, delay aversion, or something else? Journal of Child Psychology and Psychiatry, 42, 199-210.

Leung, P.W.L., \& Connolly, K.J. (1998). Do hyperactive children have motor organization and/or execution deficits? Developmental Medicine and Child Neurology, 40, 600-607.

Marakovitz, S.E., \& Campbell, S.B. (1998). Inattention, impulsivity, and hyperactivity from preschool to school age: Performance of hard-to-manage boys on laboratory measures. Journal of Child Psychology and Psychiatry, 39, 841-851. 
Mariani, M.A., \& Barkley, R.A. (1997). Neuropsychological and academic functioning in preschool boys with attention deficit hyperactivity disorder. Developmental Neuropsychology, 13, 111-129.

Nigg, J.T., Hinshaw, S.P., Carte, E.T., \& Treuting, J.J. (1998). Neuropsychological correlates of childhood attention-deficit/hyperactivity disorder: Explainable by comorbid disruptive behavior or reading problems? Journal of Abnormal Psychology, 107, 468480.

Piek, J.P., Pitcher, T.M., \& Hay, D.A. (1999). Motor coordination and kinaesthesis in boys with attention deficit-hyperactivity disorder. Developmental Medicine and Child Neurology, 41, 159-165.

Pryde, K.M., Bryden, P.J., \& Roy, E.A. (2000). A developmental analysis of the relationship between hand preference and performance: I. Preferential reaching into hemispace. Brain and Cognition, 43, 370-374.

Reich, W. (2000). Diagnostic Interview for Children and Adolescents (DICA). Journal of the American Academy of Child and Adolescent Psychiatry, 39, 59-66.

Schachar, R., Tannock, R., Marriott, M., \& Logan, G. (1995). Deficient inhibitory control in attention deficit hyperactivity disorder. Journal of Abnormal Child Psychology, 23, 411-437.

Schneider, W., \& Shiffrin, R.M. (1977). Controlled and automatic human information processing: I. Detection, search, and attention. Psychological Review, 84, 97-109.

Seitz, R.J., Stephan, K.M., \& Binkofski, F. (2000). Control of action as mediated by the human frontal lobe. Experimental Brain Research, 133, 71-80.

Shaywitz, S.E., Escobar, M.D., Shaywitz, B.A., Fletcher, J.M., \& Makuch, R. (1992). Evidence that dyslexia may represent the lower tail of a normal distribution of reading ability. The New England Journal of Medicine, 326, 145-150.
Steger, J., Imhof, K., Coutts, E., Gundelfinger, R., Steinhausen, H.C., \& Brandeis, D. (2001). Attentional and neuromotor deficits in ADHD. Developmental Medicine and Child Neurology, 43, 172-179.

Stubbe, D.E. (2000). Attention-deficit/hyperactivity disorder overview. Historical perspective, current controversies, and future directions. Child and Adolescent Psychiatry Clinics of North America, 9, 469479.

Tiffin, J. (1968). Purdue Pegboard Examiner Manual (pp. 1-115). Chicago: Science Research Associates, Inc.

Van der Meere, J., \& Sergeant, J. (1988). Acquisition of attention skill in pervasively hyperactive children. Journal of Child Psychology and Psychiatry, 29, 301310.

Van der Meere, J., Van Baal, M., \& Sergeant, J. (1989). The Additive Factor Method: A differential diagnostic tool in hyperactivity and learning disability. Journal of Abnormal Child Psychology, 17, 409-422.

Van Grimbergen, I., Célestin-Westreich, S., \& PonjaertKristofferson, I. (1999). Validering van ADIKA-IV (deel externaliserend gedrag) bij een klinische populatie kinderen tussen 6 en 18 jaar [Validation of ADIKA-IV (externalising part) in a clinical child population aged 6-18 years]. Paper presented at the second Flemish Congress of Child and Adolescent Psychiatry and Psychotherapy, Leuven, Belgium.

Verhulst, F.C., Koot, J.M., \& van der Ende, J. (1996). Handleiding voor de CBCL (Child Behavior Checklist) [Manual for the CBCL]. Rotterdam: Afdeling Kinderen Jeugdpsychiatrie, Sophia Kinderziekenhuis/Academisch Ziekenhuis Rotterdam/Erasmus Universiteit Rotterdam, the Netherlands.

Wolpert, D.M., Ghahramani, Z., \& Jordan, M.I. (1995). An internal model for sensorimotor integration. Science, 269, 1880-1882.

Manuscript accepted 30 August 2002 